\title{
Sigles bibliographiques
}

\begin{tabular}{ll} 
BCT & Bustamante, Corriente \& Tilmatine 2010-2014 \\
BDB & Brown, Drivers \& Briggs 1907 \\
DAA & Corriente 1997a \\
DAI & Corriente 1999a \\
DAX & Kasten \& Nitti 2002 \\
DCEH & Corominas \& Pascual 1980-1981 \\
DE & Dozy \& Engelmann \\
DECLC & Corominas 1983-1991 \\
DO & Oliver 2004 \\
DRAE & Diccionario de la Lengua Española (dernières éditions) \\
DS & Dozy 1881 \\
EI & Encyclopédie de l'Islam \\
FH & Benchekroun 1981 \\
GL & Corriente 1991 \\
GP & Nykl 1953 \\
IQ & Corriente 1995 et 2013 \\
IW & Banqueri 1802 \\
LHP & Corriente 2004 \\
PD & Corriente 1997b \\
SG & Simonet 1889 \\
VA & Corriente 1989a \\
& \\
\hline
\end{tabular}

